\title{
PLASMA SPRAY-PHYSICAL VAPOR DEPOSITION (PS-PVD) OF CERAMICS FOR PROTECTIVE COATINGS
}

\author{
B. J. Harder and D. Zhu, NASA Glenn Research Center, Cleveland OH 44135
}

\section{ABSTRACT}

In order to generate advanced multilayer thermal and environmental protection systems, a new deposition process is needed to bridge the gap between conventional plasma spray, which produces relatively thick coatings on the order of 125-250 microns, and conventional vapor phase processes such as electon beam physical vapor deposition (EB-PVD) which are limited by relatively slow deposition rates, high investment costs, and coating material vapor pressure requirements. The use of Plasma Spray - Physical Vapor Deposition (PS-PVD) processing fills this gap and allows thin $(<10$ $\mu \mathrm{m})$ single layers to be deposited and multilayer coatings of less than $100 \mu \mathrm{m}$ to be generated with the flexibility to tailor microstructures by changing processing conditions. Coatings of yttria-stabilized zirconia (YSZ) were applied to NiCrAlY bond coated superalloy substrates using the PS-PVD coater at NASA Glenn Research Center. A design-of-experiments was used to examine the effects of process variables (Ar/He plasma gas ratio, the total plasma gas flow, and the torch current) on chamber pressure and torch power. Coating thickness, phase and microstructure were evaluated for each set of deposition conditions. Low chamber pressures and high power were shown to increase coating thickness and create columnar-like structures. Likewise, high chamber pressures and low power had lower growth rates, but resulted in flatter, more homogeneous layers.

\section{INTRODUCTION}

Thermal and environmental barrier coatings (TBCs, EBCs) are necessary for the protection of metal and ceramic components in high temperature turbine engine environments. To meet everincreasing temperature demands for improving efficiency, these coatings have become increasingly complex in composition and architecture. Thermal spray technology has been a longstanding processing method for depositing TBCs and EBCs. ${ }^{1}$ In traditional air plasma spray (APS), coatings are formed by the buildup of molten ceramic material as a torch traverses the substrate. Electron beamphysical vapor deposition (EB-PVD) has been used to create smooth and more strain tolerant TBCs by growth of columnar grains. In this process, vaporized ceramic material condenses onto the hot substrate surface under high vacuum conditions $\left(<10^{-4}\right.$ torr). The resultant coating has a microstructure that is well suited for turbine airfoil components. ${ }^{2}$ However, these processes both exhibit limitations, as APS methods produce rough coatings on the order of 125-250 microns thick (a single pass is 50-80 microns), and conventional EB-PVD processing is limited by slower growth rates, high equipment investment costs, and coating material vapor pressure requirements.

A new processing technology, known as Plasma Spray - Physical Vapor Deposition (PS-PVD) has been developed in order to bridge the gap between conventional APS and PVD techniques to create unique microstructures. ${ }^{3,4}$ The PS-PVD system at the NASA Glenn Research Center is one of only four systems currently available at this time. Conventional low pressure plasma spray (LPPS) is a variation of traditional plasma spray by which deposition is done in a controlled environment at a reduced pressure, typically 50-200 torr. PS-PVD (also known as Very Low Pressure Plasma Spray (VLPPS) or Low Pressure Plasma Spray-Thin Film (LPPS-TF)) is a unique type of LPPS where pressures are considerably lower, ranging from 0.5-10 torr. The low operating pressure results in a plasma that can extend over 7 feet in length and 3 feet in diameter. The process produces supersonic gas streams $(\sim 2000 \mathrm{~m} / \mathrm{s})$ with temperatures in excess of $6000 \mathrm{~K}$. Although the plasma is significantly larger than standard vacuum plasma spray techniques, there is a more uniform distribution of temperature and particle velocity. ${ }^{5}$ The high power levels $(>100 \mathrm{~kW})$ at pressures below 10 torr result 
in the vaporization of the injected ceramic powder and deposition onto the target substrate. This technology has been reported to coat an area greater than 5 square feet with a $10 \mu \mathrm{m}$ layer of $\mathrm{Al}_{2} \mathrm{O}_{3}$ in less than one minute. ${ }^{4}$ The incorporation of the evaporated material into the gas stream also provides some non line-of-sight coverage, which is not possible using PVD or traditional plasma spray methods. ${ }^{6}$

The advantage of the PS-PVD technique is the flexibility to vary coating architecture with the processing conditions. Previous work has shown that thin, dense coatings can be deposited with splatlike microstructure as well as columnar, PVD-like coatings using the same chamber. ${ }^{6-8}$ The wide range of possible microstructures and fast deposition rates make this technology attractive for a wide range of applications, including wear or electrically resistive coatings, diffusion barrier layers, ion-transport layers for fuel cell components, or gas sensing membranes. ${ }^{4}$ Due to the distinctive differences between PS-PVD and traditional plasma spray deposition, operating conditions and process-properties relationships are expected to be unique and therefore must be explored. This work will focus on how variation of the processing conditions can be used to create different microstructures with a single material using PS-PVD. Here we will discuss the relationship between arc current, plasma gas ratio and total plasma gas flow on processing conditions, as well as the resulting coating phase and microstructure.

To showcase this emerging technology, we have chosen to work with yttria-stabilized zirconia (YSZ) as a model system. The literature has many examples of both splat (via APS processing) as well as columnar (via EB-PVD processing) microstructures for YSZ. ${ }^{1,9}$ Although this material is traditionally used for thermal barrier coatings, this study will assist in understanding process-properties relationships, which will be used in developing more advanced turbine EBCs for ceramic matrix composites where high temperature capability is required.

\section{EXPERIMENTAL PROCEDURE}

Samples (25.4 mm diameter, $3.18 \mathrm{~mm}$ thick) of Rene N5 and Inconel 738 superalloy substrates were grit blasted and a NiCrAlY (Ni-22Cr-10Al-Y) bond coat was applied via LPPS at APS Materials, Inc. (Dayton, OH). The backsides of the samples were spot-welded to stainless steel strips, which were in turn spot-welded to a 6" x 6” Inconel 716 plate. Two samples were mounted on the plate at a time, side by side and approximately 0.25 ” apart. The plate was mounted on the sample arm within the chamber, and set at a distance of 65" from the plasma torch. The plasma torch used was a 03CP (Sulzer Metco Inc., Westbury, NY) torch with a MultiCoat processing center, and the sample arms were controlled by a GE Fanuc CNC (Hoffman Estates, IL).

Coatings were deposited from the same batch of material; a yttria stabilized zirconia $\left(\mathrm{Zr}_{0.92} \mathrm{Y}_{0.08} \mathrm{O}_{1.96}\right)$ Sulzer Metco (Westbury, NY) 6700 powder specifically developed for vapor deposition. The powder was spray dried and sintered to a particle distribution d10, d50, and d90 of 2.5, 6.1, and 22.0 microns, respectively. The powder is delivered to the torch via a Sulzer Metco Inc. (Westbury, NY) Model SMW 60C powder feeder. The unit uses a rotating disc speed (rpm) to regulate the powder feed rate. Current was delivered to the torch from two 1000A TriStar (El Sugundo, CA) power supplies. To control the pressure in the chamber, two vacuum pumps are downstream with a blower, which controlled the pressure by setting the motor speed (rpm).

Prior to starting the torch, the chamber was evacuated to $<1$ torr, and then backfilled with Ar to $\sim 30$ torr. The plasma torch was lit, and the chamber was pumped down to a pressure of $\sim 3$ torr. The torch and sample arm were moved into position, and parameters were adjusted to preheat the substrate. The conditions for the preheating treatment are shown in Table I. After this step, the processing setpoints for the YSZ deposition condition were set and achieved within 15 seconds, at which point the powder feeding was initiated. The pressure during the 5 minute deposition was measured by a 
transducer inside of the deposition chamber, and the average values during the powder feeding were reported.

Table I: Preheating conditions for all experiments.

\begin{tabular}{lc} 
Parameter & Value \\
\hline Current (A) & 1400 \\
Ar/He Ratio & 0.8 \\
Total Plasma Gas Flow (NLPM) & 90 \\
Sample-to-torch distance (in) & 65 \\
Heating Time (s) & 60
\end{tabular}

For the design of experiments in this study, three processing variables were examined. The torch current, the Ar/He plasma gas ratio, and the total plasma gas flow were analyzed at three levels, which are shown in Table II. Many other processing conditions remained constant for all runs. Carrier gases to both powder injection ports were set at 10 NLPM (Normal Liters Per Minute) each, the sample-to-torch distance was held at 65”, the powder disc speed was set to $1 \mathrm{rpm}(\sim 0.3 \mathrm{~g} / \mathrm{s})$, the blower speed was held constant at $1200 \mathrm{rpm}$, and deposition time was 5 minutes. Design-Expert Version 8.0.1 software (Stat-Ease, Minneapolis, MN) was used to generate the run order and analyze how the input parameters affect the chamber pressure and deposition power.

Table II: Varied conditions for the design of experiments.

\begin{tabular}{lc} 
Parameter & Value \\
\hline Current (A) & $1400,1600,1800$ \\
Ar/He Ratio & $1: 2,1: 1,2: 1$ \\
Total Plasma Gas Flow (NLPM) & $80,100,120$ \\
\hline
\end{tabular}

After deposition, the coatings were X-rayed for phase ID using a Bruker D8 Advance diffractometer (Madison, WI). After X-raying the surface, samples were cut, mounted, and polished to a 1 micron diamond finish. Thicknesses were measured for all of the coatings using a Zeiss (Oberkochen, Germany) optical microscope. Average thicknesses were determined over a 500 micron distance, and seven such areas were chosen randomly across the entire cross-section. The average value was used as the coating thickness for the particular set of conditions.

\section{PROCESS MODELING}

The PS-PVD process is a new technique, and the facility at NASA-Glenn is a custom-built system. Therefore, it is essential that the process-property relationships are well established. While many process variables can be controlled, understanding the process through the plasma and at the substrate is the most effective way to control the coating deposition. Since this is a custom system, the effect of process variables on deposition conditions is not fully understood. Therefore, a statistical model was utilized to understand the influence of Ar/He plasma gas ratio, total plasma gas flow, and torch current. The effect of these processing variables was measured by chamber pressure and torch power, which will be discussed as the deposition conditions. Both chamber pressure and torch power are expected to be highly influential on substrate temperature and growth rate. Low chamber pressures increase the plasma length and width, which better envelops the target. Elevated power conditions will increase the overall plasma temperature, which may heat the substrate more effectively. Unfortunately due to grounding effects from the chamber/sample arm, we were unable to accurately measure the 
temperature during coating deposition, but visual observation and measurement of the substrate temperature after deposition supported these assumptions.

To understand and quantify the influence of the processing variables (Ar/He ratio, total plasma gas, current) on chamber pressure and torch power, a design of experiments was utilized. Our experimental design called for 3 variables to be examined at 3 levels. To evaluate the deposition conditions as a function of the process variables, a quadratic model was considered to encompass the first and second order effects, as well as any two-way interactions. In a traditional (full-factorial) experimental matrix of 3 variables at 3 levels, 27 experiments are required to separate all first and second order effects, as well as any two-way interactions between the variables, not including replicants. To minimize the number of experiments needed, we employed a d-optimal strategy to limit the number of runs to 20, which included 5 replicants. Additional repeats (replicants) were important since they helped to determine the consistency at a single deposition condition. Terms that were not considered statistically significant (confidence $>90 \%$ ) were removed from the model. The run conditions and resulting deposition conditions (pressure and power) are shown in Table 3.

Table III: Summary of the data for the coatings created using the design of experiments.

\begin{tabular}{|c|c|c|c|c|c|c|}
\hline $\begin{array}{c}\text { Run } \\
\text { Order }\end{array}$ & $\begin{array}{c}\text { Ar/He Plasma } \\
\text { Gas Ratio }\end{array}$ & $\begin{array}{c}\text { Total Plasma } \\
\text { Gas (NLPM) }\end{array}$ & $\begin{array}{c}\text { Current } \\
\text { (Amperes) }\end{array}$ & $\begin{array}{c}\text { Chamber } \\
\text { Pressure (torr) }\end{array}$ & $\begin{array}{c}\text { Torch } \\
\text { Power } \\
(\mathrm{kW})\end{array}$ & $\begin{array}{c}\text { Thickness } \\
\text { (microns) }\end{array}$ \\
\hline 1 & $2: 1$ & 100 & 1600 & 1.28 & 74.6 & 18.2 \\
\hline 2 & $1: 2$ & 80 & 1800 & 1.08 & 84.6 & 30.2 \\
\hline 3 & $1: 2$ & 80 & 1400 & 1.08 & 61.1 & 14.9 \\
\hline 4 & $1: 2$ & 120 & 1400 & 1.49 & 67.6 & 11.6 \\
\hline 5 & $1: 1$ & 100 & 1600 & 1.27 & 80.2 & 22.7 \\
\hline 6 & $1: 1$ & 100 & 1600 & 1.27 & 78.9 & 20.6 \\
\hline 7 & $1: 2$ & 100 & 1600 & 1.28 & 79.5 & 25.4 \\
\hline 8 & $1: 1$ & 120 & 1600 & 1.48 & 82.1 & 13.6 \\
\hline 10 & $1: 1$ & 100 & 1600 & 1.28 & 78.2 & 20.4 \\
\hline 11 & $1: 1$ & 100 & 1600 & 1.29 & 76.9 & 22.7 \\
\hline 12 & $1: 1$ & 100 & 1400 & 1.27 & 62.4 & 9.6 \\
\hline 14 & $2: 1$ & 80 & 1400 & 1.09 & 57.1 & 12.7 \\
\hline 15 & $1: 1$ & 100 & 1800 & 1.31 & 86.4 & 27.5 \\
\hline 16 & $1: 1$ & 100 & 1600 & 1.29 & 75 & 15.5 \\
\hline 17 & $2: 1$ & 120 & 1800 & 1.49 & 89.4 & 9.5 \\
\hline 18 & $2: 1$ & 80 & 1800 & 1.11 & 82 & 25.5 \\
\hline 19 & $1: 1$ & 120 & 1400 & 1.49 & 64 & 2.6 \\
\hline 20 & $1: 1$ & 120 & 1800 & 1.50 & 92.3 & 18.6 \\
\hline & $1: 1$ & 100 & 1600 & 1.30 & 75 & 22.7 \\
\hline
\end{tabular}

Control of chamber pressure is essential to the coating process, since it influences the plasma diameter and length. Figure 1 is a plot of the chamber pressure against total plasma gas. All 20 depositions are included in the chart and the variability in the vacuum level during the deposition varied by $\pm 0.03-0.05$ torr, which accounted for the spread in the data at each pressure. For equivalent pumping conditions, the pressure was insensitive to both current and Ar/He ratio. Therefore for the experimental parameters in this study, the viscosity of the gas (which would be affected by the ratio 
and current) does not impact the deposition condition and the total plasma gas was found to be the only factor influencing the chamber pressure. The standard error for the empirical model was 0.013 torr, and the $\mathrm{R}^{2}$ value was 0.99 .

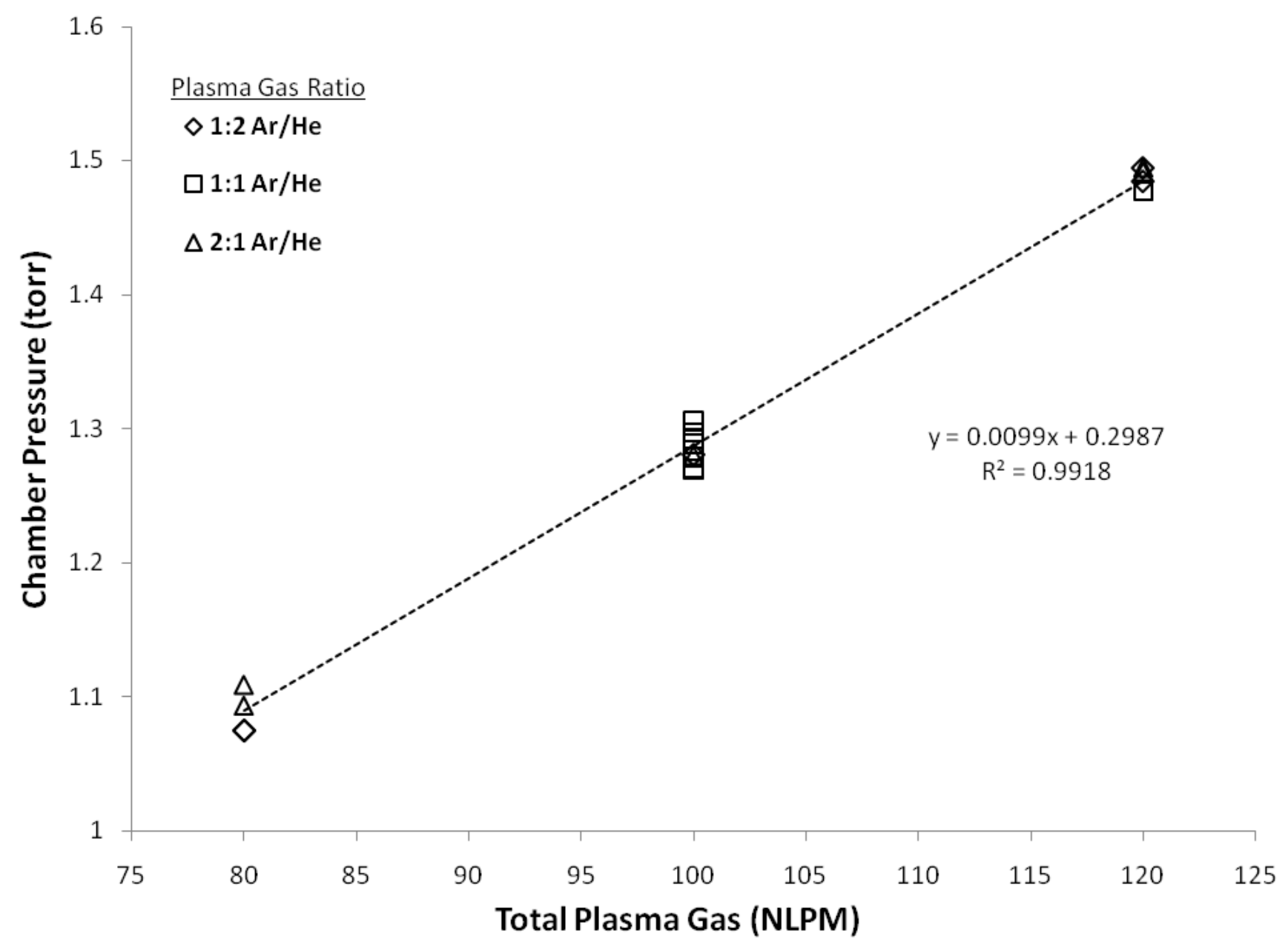

Figure 1. Plot of chamber pressure as a function of total plasma gas. The pressure was insensitive to current and gas ratio.

The torch power results in Table III were measured as the product of arc voltage and the supplied amperage. The empirical model (standard error $=1.40 \mathrm{~kW}, \mathrm{R}^{2}=0.98$ ) for plasma power at the two different gas mixtures is plotted in Figure 2. First order effects were observed for all three variables, as well as a second order effect from the current. A lower Ar/He ratio also served to increase the torch power, which was expected. Increasing the helium content serves to increase the plasma enthalpy and generate more heat. Higher plasma gas flow rates (total plasma gas) elevated the power by pushing the arc was farther out of the torch, which increased the voltage. Given equivalent current settings, higher plasma gas flow rates therefore produce a higher power plasma. 


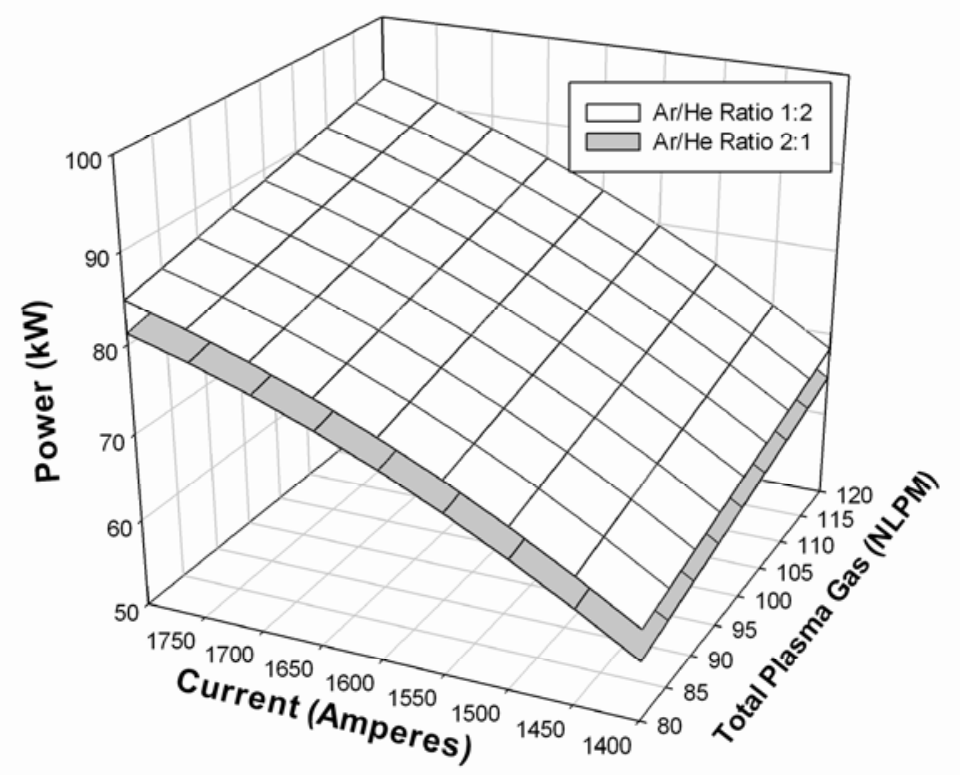

Figure 2. The empirical model surfaces of the measured torch power at Ar/He ratios of 1:2 and 2:1.

The aforementioned models provide a basic understanding of how some of the PS-PVD processing variables influence the deposition conditions. The empirical models of the deposition conditions are independent of coating material. Therefore, these relationships should hold true regardless of the coating system and substrate material. With these models, the effect of chamber pressure and torch power can be examined on the properties of a single coating material.

\section{RESULTS - COATINGS}

The deposition conditions discussed above have a significant effect on coating microstructure and properties. Coating thickness, phase composition, and microstructure were examined as a function of chamber pressure and torch power. The thicknesses reported in Table III were averages of optical microscopy measurements across each sample. In Figure 3 coating thickness is shown as a function of torch power and grouped in similar pressures to examine the effect of both conditions. High power and low pressure resulted in the thickest coatings, and these trends were consistent for the 1.1 and 1.3 torr conditions. The low growth rate and significant scatter observed at high pressures (1.5 torr) may be a consequence of a reduced amount of vapor phase available due to the standoff distance. A reduction in the torch-to-sample distance may limit the spread in the data or reduce the effect on coating thickness, but this is outside the scope of this current study. 


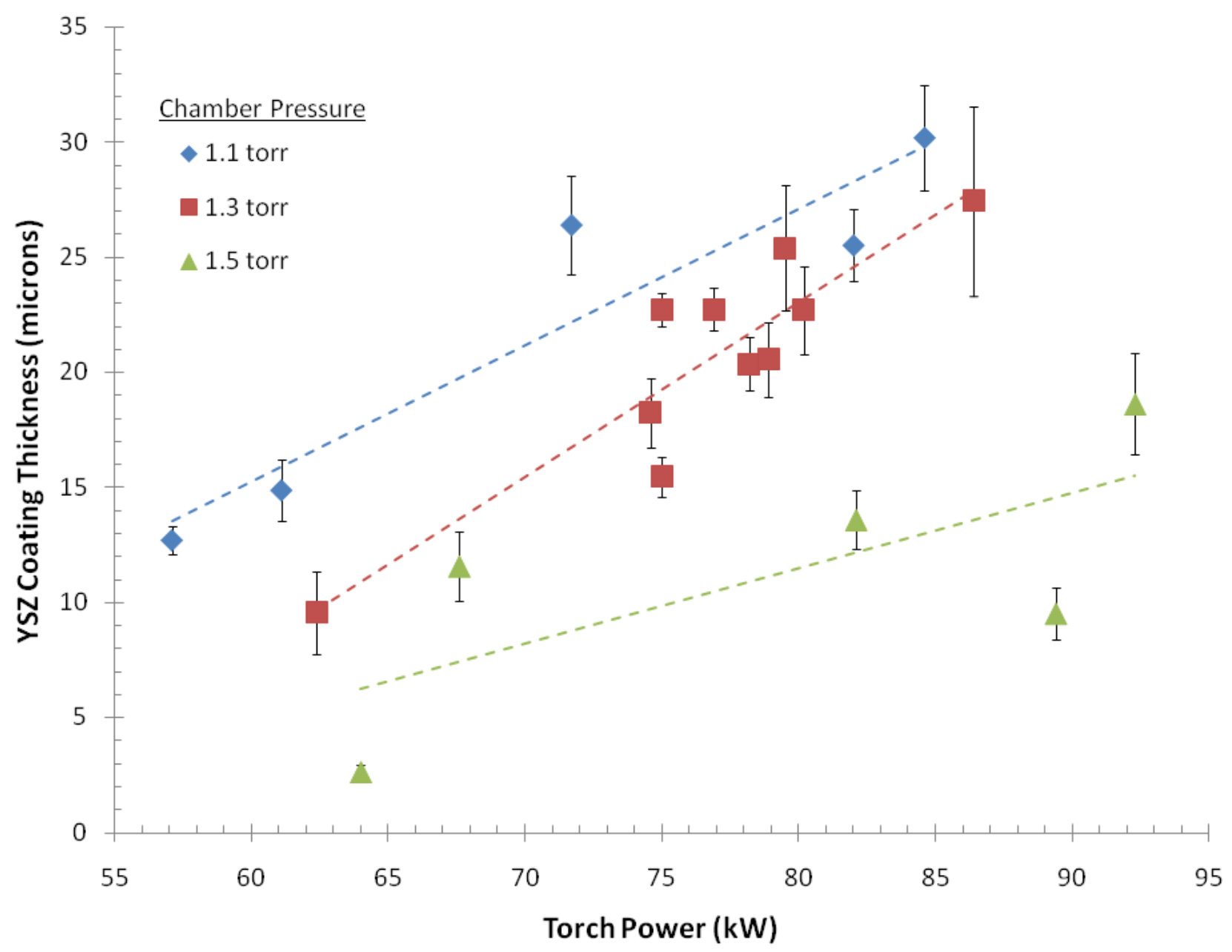

Figure 3. Plot of coating thickness as a function of torch power. The dashed lines are a linear fit of the data to show the trends for like chamber pressure conditions, and the error bars shown are the standard deviation of the coating thickness across the sample surface.

The coatings were also X-rayed for phase identification. Examples of as-sprayed diffraction patterns for 3 growth conditions and the as-received powder are shown in Figure 4. The majority of the deposited coatings was tetragonal YSZ as expected. However, in the lowest enthalpy conditions (which were also the thinnest coatings), traces of monoclinic zirconia and yttria were observed. The starting YSZ powder was spray dried and sintered and the as-received powder (bottom curve of Figure 4) consisted of a mixture of $\mathrm{Y}_{2} \mathrm{O}_{3}$ and $\mathrm{ZrO}_{2}$. In the PS-PVD process, the particles are vaporized and mixed within the plasma. The presence of monoclinic $\mathrm{ZrO}_{2}$ and cubic $\mathrm{Y}_{2} \mathrm{O}_{3}$ in the top curve of Figure 4 may have resulted from inadequate mixing of the two materials during processing. Under the high enthalpy conditions, the plasma was more homogeneous in composition (effectively mixed within the plasma) and the YSZ was deposited in the tetragonal phase. This trend is consistent with the third curve from the top in Figure 4, which corresponded to the high enthalpy condition. The as-sprayed coating is nearly $100 \%$ tetragonal YSZ. Thin coatings also showed a larger signal of the NiCrAlY bondcoat (due to coating thickness) as shown in the top curve in Figure 4. The as-sprayed coatings did not exhibit obvious evidence of texture, even in those with the most 'columnar' microstructures. This is likely due to the much wider columns, reduced orientation, and bondcoat roughness in the PS-PVD coatings than is observed in traditional EB-PVD methods. 


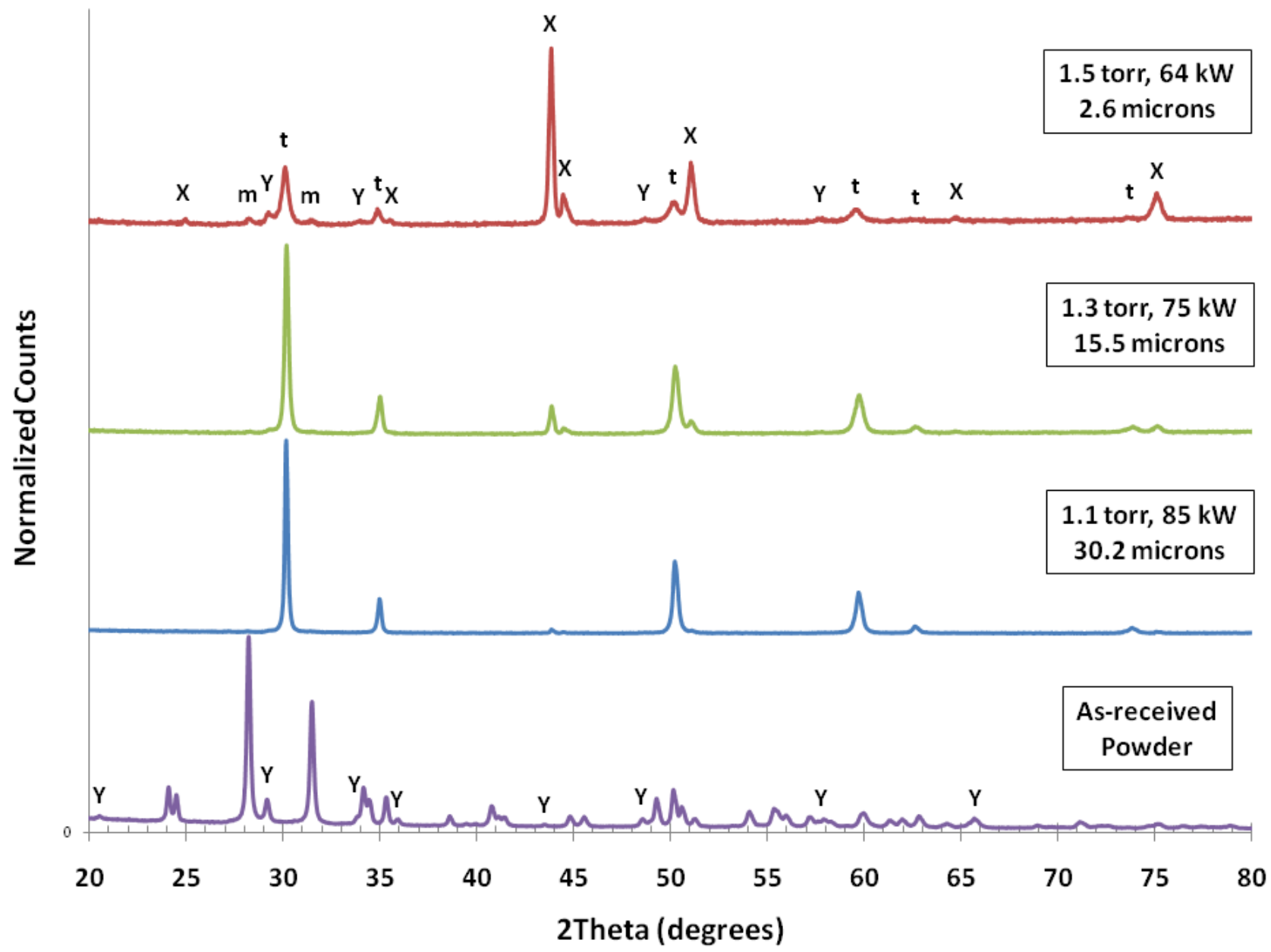

Figure 4. X-ray diffraction patterns of three different PS-PVD deposited YSZ coatings (top to bottom- experimental number 17, $10,2)$ and the as-received YSZ powder. " $X$ " designates the NiCrAIY bond coat, "Y" designates the cubic Y2O3 phase, " $t$ " designates the tetragonal YSZ phase, and " $\mathrm{m}$ " designates the monoclinic ZrO2 phase. Note that the thinnest coating shows the largest amount of monoclinic ZrO2 and cubic Y2O3. The as-received powder is a mixture of monoclinic ZrO2 and cubic Y2O3. The yttria peaks are labeled with "Y," and all other peaks correspond to the monoclinic ZrO2.

Sample microstructures varied significantly with the deposition conditions. However, all 20 experimental conditions resulted in deposition along the sides of the substrate in addition to the surface, indicating that the YSZ was applied via the vapor phase. On average, high power, low vacuum conditions produced columnar-like coatings. High chamber pressures and low power produced flatter, more homogenous layers. It was possible to observe both types of microstructures in a single sample, and they were distributed evenly across the sample cross-section. Examples of columnar-like microstructures are shown in Figure 5. The direction of column growth was perpendicular to the torch direction and substrate surface. Although some degree of deposition occurred along the sides of the substrates with the same microstructure, the surface normal to the plasma was thicker. Column widths for the highest power/lowest pressure conditions were 10-20 microns, which are thicker than standard PVD growth methods, which produce column widths on the order of 5-10 microns. ${ }^{9}$ Lower power settings (and likely lower substrate temperatures) resulted in wider columns. Coating thicknesses did not have any impact on column width. In Figure 5(a) and (b), the columns are tightly packed and a consistent growth is seen across the substrate surface. These images were of the coating deposited during sample run number 2, which corresponded to the low vacuum (1.1 torr), high power ( $84.2 \mathrm{~kW}$ ) condition. Figure 5(c) and (d) show coating microstructure deposited during run number 10, which had a higher chamber pressure (1.29 torr) and a lower power 
$(76.9 \mathrm{~kW})$. The columnar-like microstructure is still present, especially on the peaks of the bondcoat, which is likely where the local temperature was highest. However, the growth is much less uniform than those obtained under high power condition, as the columns are spaced further apart than those in (a) and (b). In Figure 5(a)-(d), both coatings show evidence of periodic renucleation and grain growth, which indicates the substrate temperature was lower than ideal for columnar growth. ${ }^{10}$ It would be expected that higher substrate temperatures would result in thinner, more tightly packed columns.

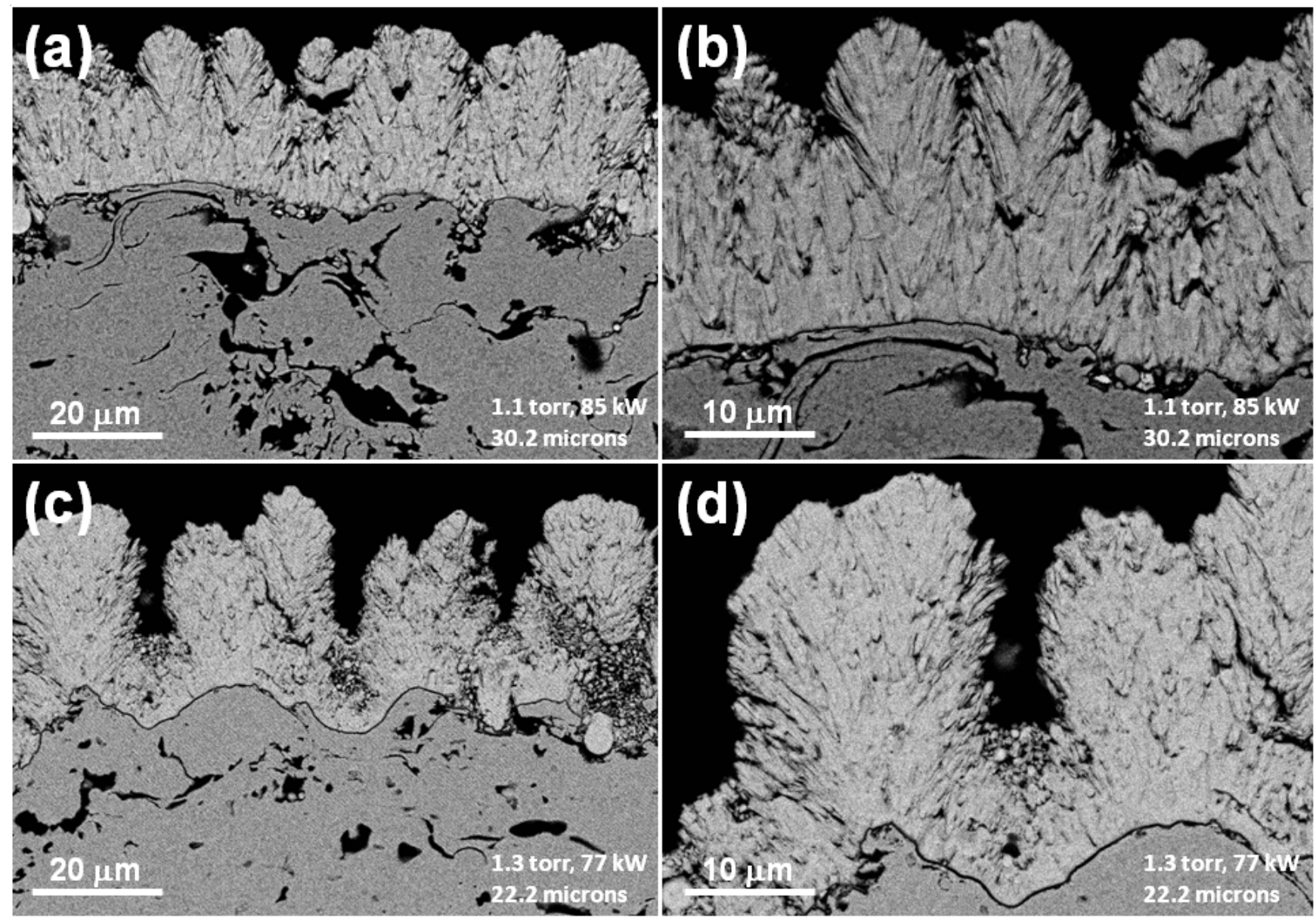

Figure 5. Backscatter images of coating cross-sections of which the light region is YSZ and the dark region is the MCrAIY bondcoat. (a) Coating deposited using conditions in run number 2 (low pressure and high power), and a higher magnification is shown in (b). (c) Coating deposited using conditions in run number 10 (model centroid), and a higher magnification is shown in (d).

Examples of flat, more homogeneous coating microstructures are shown in Figure 6. A thin ( $\sim 3$ micron) dense coating is seen in the micrographs in Figure 6(a) and (b), which corresponds to one of the lowest power (64 kW) and highest pressure (1.49 torr) conditions. Figure 6(c) and (d) were obtained from deposition number 10 (pressure $=1.29$ torr, power $=76.9 \mathrm{~kW}$ ), which was representative of the center of the design space, and were from the same sample as Figure 5(c) and (d). These images illustrate that both columnar and flat microstructures were found on a single sample. Sample with a large standard deviation in thickness (shown in Figure 3) corresponded to those where both microstructures were readily observed. The larger standard deviation is a result of a bimodal distribution in the microstructure. The coating in Figure 6(c) and (d) also shows a large amount of void space, as well as short, discontinuous columns. This porous structure suggests a 'mixed mode' of deposition. Spinhirne et al. saw a similar effect using the Low Pressure Plasma Spray - Thin Film rig located at Sandia National Laboratory, and attributed this to a substrate temperature that was too low 
for consistent column growth. ${ }^{11}$ The ability to form a dense coating, as seen in Figure 6(a) and (b), may be attributed to the higher chamber pressure. At a pressure of 1.49 torr, the plasma is considerably shorter, and the vaporized YSZ is more likely to cool before it reaches the substrate. Therefore, the growth rate is considerably lower and there is less opportunity for void space to form as the coatings grow.
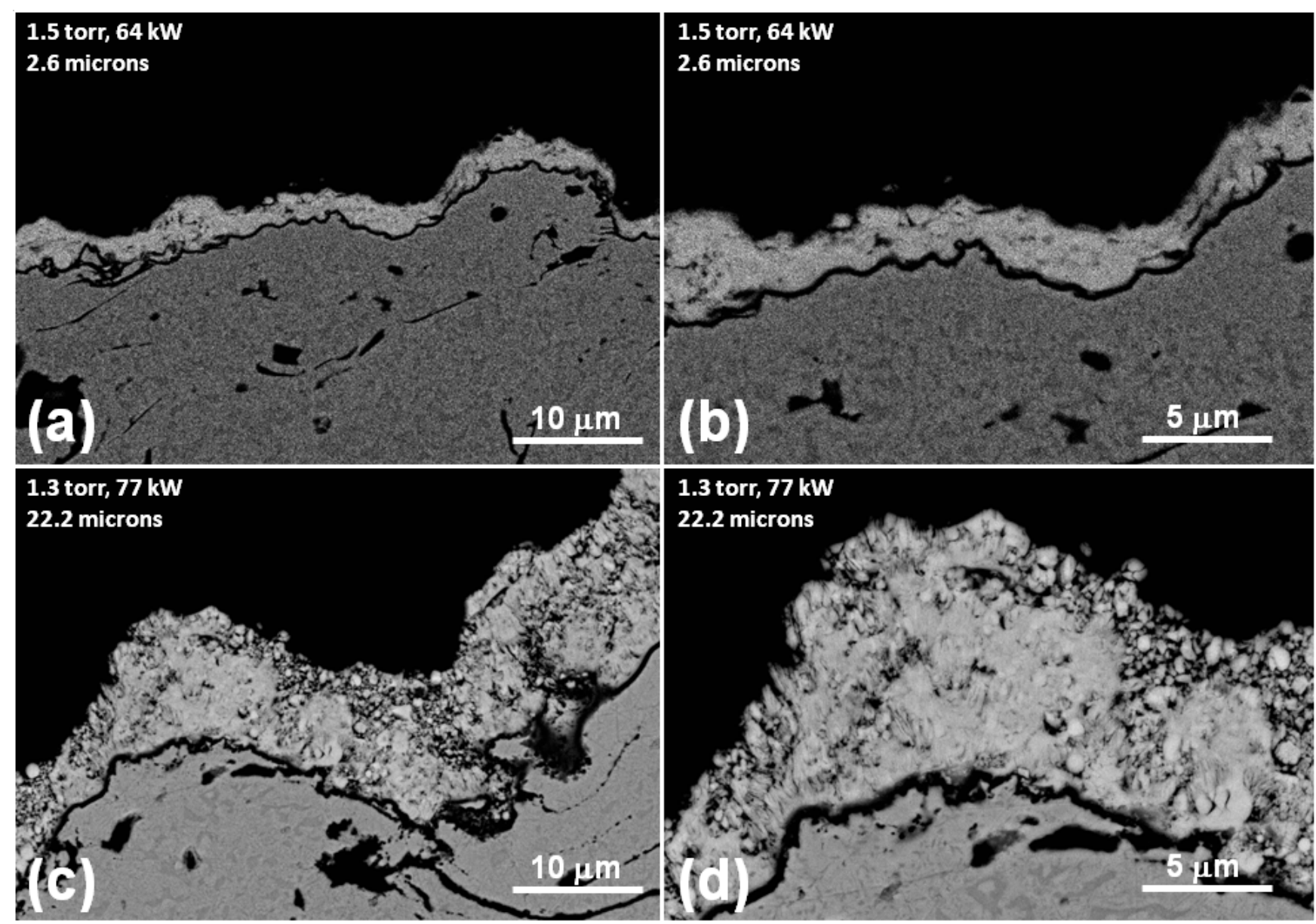

Figure 6. Backscatter images coating cross-sections of which the light region is YSZ and the dark region is the MCrAlY bondcoat. (a) Coating deposited using conditions in run number 17 (lowest power, highest pressure), and a higher magnification is shown in (b). (c) Coating deposited using conditions in run number 10 (model centroid), and a higher magnification is shown in (d).

\section{CONCLUSIONS}

The capabilities of the new processing technology, Plasma Spray-Physical Vapor Deposition (PS-PVD), was explored using yttria-stabilized zirconia as a model material. The resultant coatings were not optimized for any type of durability or structure. This study was undertaken to examine how some of the processing variables of the PS-PVD technology influence deposition conditions and coating microstructure. It was shown that chamber pressure scaled with total plasma gas, and that structure and coating thickness were influenced by torch power and chamber pressure. As with most plasma spray technologies, the PS-PVD process is influenced by many variables, and it is not possible to fully describe the conditions for generating fully tailored microstructures with a single round of experiments. Future work will investigate additional factors such as the influence of substrate temperature and the effect of processing variables on performance. 


\section{ACKNOWLEDGEMENTS}

This work was funded by the Supersonics Project under the Fundamental Aeronautics Program. The authors would also like to thank Mary Ann Meador and Rick Rogers of NASA Glenn Research Center (GRC), Joy Buehler and Mike Cuy of ASRC, NASA GRC Division, as well as Bob Pastel of SLI, NASA GRC Division, for valuable discussions and contributions to this work.

\section{REFERENCES}

1.) R. A. Miller, "Current Status of Thermal Barrier Coatings - An Overview," Surface \& Coatings Technology, 30[1] 1-11 (1987).

2.) A. G. Evans, D. R. Mumm, J. W. Hutchinson, G. H. Meier, and F. S. Pettit, "Mechanisms controlling the durability of thermal barrier coatings," Prog. Mater. Sci., 46[5] 505-53 (2001).

3.) A. Refke, G. Barbezat, J.-L. Dorier, M. Gindrat, and C. Hollenstein, "Characterization of LPPS Processes Under Various Spray Conditions for Potential Applications," Proceedings of the International Spray Conference, May 5-8, (Orlando, FL), 581-88 (2003).

4.) A. Refke, M. Gindrat, K. v. Niessen, and R. Damani, "LPPS Thin Film: A Hybrid Coating Technology between Thermal Spray and PVD for Functional Thin Coatings and Large Area Applications," Proceedings of the International Thermal Spray Conference, May 14-18, (Beijing, China), 705-10 (2007).

5.) J. L. Dorier, M. Gindrat, C. Hollenstein, M. Loch, A. Refke, A. Sailto, and G. Barbezat, "Plasma Jet Properties in a New Spraying Process at Low Pressure for Large Area Thin Film Deposition," Proceedings of the International Thermal Spray Conference, May 28-30, (Singapore, Singapore), 759-64 (2001).

6.) K. von Niessen, M. Gindrat, and A. Refke, "Vapor Phase Deposition Using Plasma Spray-PVD (TM)," Journal of Thermal Spray Technology, 19[1-2] 502-09 (2010).

7.) A. Hall, J. McCloskey, D. Urrea, T. Roemer, D. Beatty, N. Spinhirne, and D. Hirschfeld, "Low Pressure Plasma Spray - Thin Film at Sandia National Laboratories," Proceedings of the International Spray Conference, May 4-7, (Las Vegas, NV), 725-28 (2009).

8.) A. Hospach, G. Mauer, R. Vaßen, and D. Stöver, "Columnar-Structured Thermal Barrier Coatings (TBCs) by Thin Film Low-Pressure Plasma Spraying (LPPS-TF)," Journal of Thermal Spray Technology, 20[1-2] 116-20 (2011).

9.) U. Schulz, K. Fritscher, and M. Peters, "EB-PVD Y2O3- and CeO2/Y2O3-stabilized zirconia thermal barrier coatings - Crystal habit and phase composition," Surface \& Coatings Technology, 82[3] 259-69 (1996).

10.) K. Wada, N. Yamaguchi, and H. Matsubara, "Crystallographic texture evolution in $\mathrm{ZrO}_{2}-\mathrm{Y}_{2} \mathrm{O}_{3}$ layers produced by electron beam physical vapor deposition," Surface \& Coatings Technology, 184[1] 55-62 (2004).

11.) N. Spinhirne, D. Hirschfeld, A. Hall, and J. McCloskey, "The Development and Characterization of Novel Yttria-Stabilized Zirconia Coatings Deposited by Very Low Pressure Plasma Spray," Proceedings of the International Spray Conference, May 4-7, (Las Vegas, NV), 750-55 (2009). 